\title{
Public Health Ethics and Conflict of Interests
}

\section{Ética em Saúde Pública e Conflito de Interesses}

António JÁCOMO田

Acta Med Port 2017 Jan;30(1):5-6 - http://dx.doi.org/10.20344/amp.8165

Keywords: Applied Research; Conflict of Interest; Ethics; Public Health; Scientific Integrity

Palavras-chave: Conflito de Interesse; Ética; Integridade Científica; Investigação Aplicada; Saúde Pública

The problem of conflict of interest in Public Health is currently one of the most debated issues discussed in the field of scientific integrity. One reason for this is that, in the last few years we have come to realize that we are experiencing the deepest crisis in the history of medicine, due to something you do not normally think about when you're a doctor - something concerned with how much good you do for people, which is the cost of health care. There is not a country in the world that now is not asking whether we can afford the work that doctors do. The political fighting that we have created centres on whether it is the government or insurance companies that are the problem. The answer to this is both yes and no. Since public health activities take a population-based approach, the intervention is often complex; involving multiple risk factors, stakeholders.

Over and above a variety of scientific tools (such as behavioural tools and those related to social science and communication science), for public health decision making another critical tool is needed: a public health ethics. Public health ethics brings such considerations as principles and values to discussions of public health policies and actions. We are convinced that this discussion, due to its theoretical nature, may raise some issues associated with its application in the context of ethical issues in public health policies, but the goal is clear: to enhance the association of the ethical elements to the challenges of social engagement of public health policies.

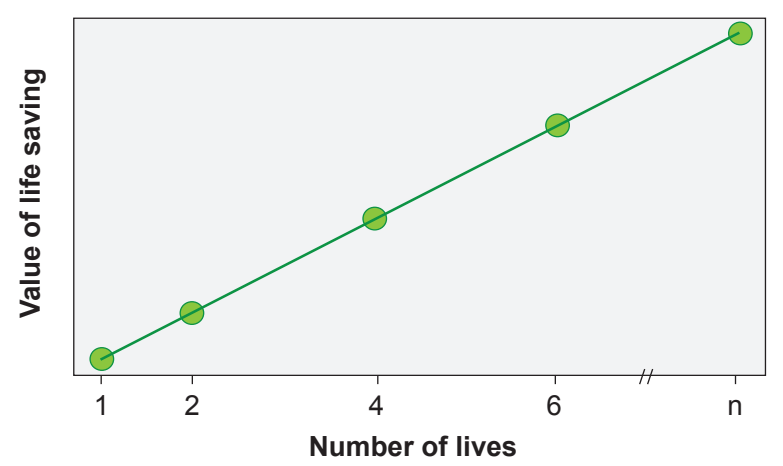

Figure 1 -A normative model for valuing the saving of human lives. Every human life is of equal value. (Reproduced from: Slovic P. Psychic numbing and genocide. Judgment and Decision Making. 2007). ${ }^{2}$

1. Instituto de Bioética. Universidade Católica Portuguesa. Porto. Portugal.

$\triangle$ Autor correspondente: António Jácomo. ajacomo@porto.ucp.pt

Recebido: 01 de setembro de 2016 - Aceite: 24 de novembro de 2016 | Copyright @ Ordem dos Médicos 2017
The principles and values, which guide public health, can differ from those that guide actions related to individual clinical medical problems.

The aim of public health ethics is to build a public health ethics infrastructure, providing tools for analysing ethical issues. One of the current examples of this distinction is the conflict between the principle of autonomy and the principle of justice associated with drug policy. The ethical question that arises is how far the rationalization of scarce resource allocation interferes with the individual's right of access to healthcare.

"From an ethical point of view, public health activities are generally understood to be teleological (end-oriented) and consequentialist - the public's health is the primary [end] goal and outcome that are sought in terms of measuring success". 1

The complexity of Public Health asks for the help of global research and, in this context, the psychology of populations is essential to attain an inclusive interpretation. We have chosen a particular psychological theory that demonstrates how difficult the approach might be, and how often the strategy may be wrong: The identified individual victim effect (Fig. 1). Psychological theories and data confirm what keen observers of human behaviour have long known. ${ }^{2}$ Statistical representations of human lives do not necessarily do justice to the importance of those lives (Fig. 2). All too often the numbers represent dry statistics,

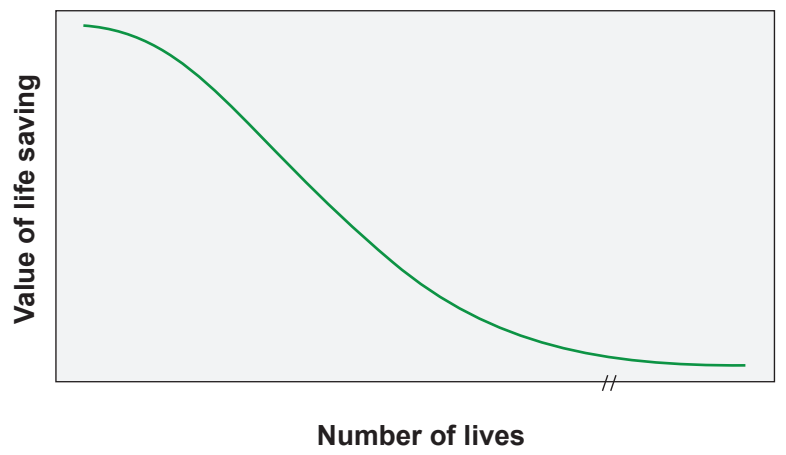

Figure 2 - A model depicting psychic numbing - the collapse of compassion - when evaluating the saving of lives. (Reproduced from: Slovic P. Psychic numbing and genocide. Judgment and Decision Making. 2007). ${ }^{2}$ 
'human beings with the tears dried off', which lack feeling and fail to motivate action.

When it comes to prompting compassion, the identified individual, with a face and a name, is unique. Psychological experiments demonstrate this clearly, but we all know this as well from personal experience and media coverage of heroic efforts to save individual lives. But the face needs not even be human to motivate powerful intervention.

For public health research specificity, maintaining high criteria of scientific integrity is essential. But what is scientific integrity? There is a predisposition to see it in terms of a marginal approach. We might consider integrity as staying within the guidelines of research ethics regulations. It means performing according to the research guidelines, and appropriate outlooks. The question is whether what is in fact immoral can be considered moral.

The resources of what could be considered relevant for research integrity might be comparable to working in public health research.

"Most approaches to promoting integrity in research are principle-based in that they portray ethical conduct as consisting of adherence to ethical rules, duties, or responsibilities". ${ }^{3}$ The problem is that these codes of conduct based on pre-established rules may not respond to the specific research needs. I point four examples of ethical issues raised by conflicts of interests:

1. - The border between the use of data (from the information systems) for diagnostic purposes of population status or for the definition of intervention strategies, and the use for research purposes.

2. - Access to non-aggregated information through information systems available in the public health area (SIARS, MIM@UF, SINUS, etc.) used with research purposes, without consideration by an ethical committee;

3. - The sharing of data between information systems without consent of the user, for purposes different from those for which the data were provided (information systems integration and data sharing);

4. - The need for an evaluation committee for local or national projects in public health, taking into account their specificities.

Further to the previous analysis of the specificity of scientific integrity, it is important to safeguard two ethical areas in public health research:

- The virtues of the professionals who run the research

- The principles that should be the basis for the design and execution of the studies.

In this regard, we propose to incorporate both perspectives into ethical proposal concerning the conflict of interest, and the reason for this is clear: "virtue-based and principle-based approaches to ethics are complementary and both can help promote research integrity". ${ }^{3}$ Although this proposal has roots in the Aristotelian model of 'virtue ethics', it overcomes this perspective by including a circumstantial element based on the research context.

In practice, the aim is that the axiological framework of researchers in public health policies be continuously reviewed in what regards short term and long term ethical challenges.

Scientific integrity in Public Health requires much more than the traditional research ethics rules and regulations. This does not mean that such guidelines are minor, but that they are only the beginning for the development of integrity. Several aspects of scientific misbehaviour are the most detectable forms of infringement of the meaning of scientific integrity. Still, the strategy to scientific integrity is the progress of ethic researchers, proficient to handle responsibility for their outcomes.

Instruction and mentoring is an important part of encouraging ethical behaviour[s] as a vital aspect of education within the fields of biomedicine, epidemiology and other areas of public health research. All participants in the pursuit of science have the responsibility to visibly follow and foster the highest standards of ethics and scientific integrity.

"Further research on ethics education should be conducted to describe the virtues that operate in science, explore how scientists learn moral virtues, and determine the extent to which virtues have an impact on scientific thinking and behaviour". ${ }^{3}$

"If we accept the principle of applying ethical principles to decision-making, informed by evidence and theory, it makes sense to widen the concept of logic modelling to 'ethical logic modelling', using the decision-making triangle rather than evidence and theory alone to judge what actions should and should not be included and implemented". ${ }^{4}$

\section{REFERENCES}

1. Childress JF, Faden RR, Gaare RD, Gostin LO, Kahn J, Bonnie RJ, et al. Public health ethics: mapping the terrain. J Law Med Ethics. 2002;30:170-8.

2. Slovic P. If I look at the mass I will never act. Judgm Decis Mak. 2007:79.

3. Resnik DB. Ethical virtues in scientific research. Account Res.
2012;19:329-43.

4. Tannahill A. Beyond evidence - to ethics: a decision-making framework for health promotion, public health and health improvement. Health Promot Int. 2008;23:380-90 